\title{
A insuficiência de um cristianismo emocional
}

\author{
Francisco de Assis Souza dos Santos
}

\section{Resumo}

O ser humano é extremamente criativo quando se trata de demonstrar emoções. O cristianismo tornou-se uma das formas mais completas de manifestação das emoções humanas ao longo da história. Pelas conhecidas sete artes (cinema, música, literatura, pintura, teatro, dança e escultura), o homem tenta comunicar sentimentos e emoções que parecem se alojar no mais profundo de seu ser. Para que essa comunicação se estabeleça, ele cria uma linguagem que possa alcançar a todos os seus assemelhados. Com a religião, o homem procura transmitir o que pensa sobre o transcendente. Usa os recursos que a arte lhe permite na tentativa de representar o Deus invisível. Contudo, só a emoção não é suficiente para torná-lo um cristão maduro. É importante perceber nos evangelhos o modo como Jesus, ao pregar o Reino de Deus, não se deixou dominar por sentimentos e emoções que, ao invés de promoverem a relação equilibrada e madura com Deus, contribuíram para excessos que em nada refletiam o amor do Pai pelos homens.

Palavras-chave: Cristianismo, Emoção, Maduro, Equilíbrio. 


\begin{abstract}
Human beings are extremely creative when it's concerning to show their emotions. Christianity has become one of the most complete manifestation of human emotions throughout the History. Through the seven known Arts (Cinema, Music, Literature, Painting, Theater, Dance and Sculpture) he tries to communicate his feelings and emotions that seem to lodge in the deepest of his being. For this communication to establish he creates a language that can, if possible, reach everyone who resemble him. With religion, the man seeks to transmit what he thinks about the transcendent. He uses the resources that Art allows him to attempt to represent the invisible God. However, only the emotion is not enough to make him a mature christian. It is important to notice through the Gospels, like Jesus as he preaches the God's kingdom, he didn't let himself be overwhelmed by feeling and emotions that instead of promoting a balanced and mature relationship with God contributed to excess that didn't reflect the Father's love for the men at all.
\end{abstract}

Keywords: Christianity, Emotions, Mature, Balanced.

\title{
Introdução
}

A questão que nos propomos analisar está ligada ao que denominamos de cristianismo emocional. É questão relevante na medida em que buscamos entender que o momento por que passa o cristianismo na América Latina, e especialmente no Brasil, dá mostras de que o emocional, em relação à fé e suas manifestações começam a dar sinais de que um cristianismo que se volte apenas para questões emocionais tende ao desequilíbrio, comprometendo o objetivo maior da fé, que dentre outros, pode ser entendido como o relacionamento maduro com Deus, consigo mesmo e com o próximo. O que poderá advir do não entendimento de uma vida cristã equilibrada é o enfraquecimento da fé e a nítida impressão de que o evangelho não consegue alcançar o coração do ser humano, suscitando neste uma sensação de desamparo e solidão, fatores emocionais que se mostram presentes nos mais diversos seguimentos sociais, bem como nas artes, na música e especialmente na religião. Outro dado importante é saber a diferença entre emoção e sentimento. Sabemos que o dualismo (o cogito) de Descartes com respeito à natureza contribuiu para que a forma de perceber o ser humano ficasse submetida a duas dimensões, a res cogitans, a "coisa 
pensante" e o da matéria, a res extensa, a "coisa extensa". ${ }^{1}$ Mas este não é o objetivo de nosso estudo. No entanto qualquer forma de cristianismo que não equilibre o emocional e o sentimental poderá incorrer em extremos que tendem a distanciar do modelo encontrado em Cristo: de uma vida plena e em perfeita harmonia com Deus.

\section{O que seria a emoção?}

As emoções humanas não são de fácil definição. Diversos fatores devem ser levados em consideração ao se tentar chegar o mais próximo possível da manifestação emocional. Delgado nos alerta, em relação aos ânimos humanos:

Uma causa de efeito comparável com o humor normal, prolongado por emoções violentas, é o que chamou JURT SCHNEIDER de reação de fundo. Consiste no impacto dos estados orgânicos (como um traumatismo cerebral ou uma enxaqueca)ou psíquicos (p.e., um desgosto) num novo ciclo de sentimentos. É o que podemos chamar de efeito causal, não motivacional, desses estados. $\mathrm{O}$ anormal desse impacto inclui não só a falta de riqueza e flexibilidade para a vida emocional, mas a intensidade e duração da influência sobre as vicissitudes do principal evento de maior dinâmica emocional. (Tradução nossa). ${ }^{2}$

Condições internas individuais e expressões externas compõem o que alguns dos estudiosos entendem como emoção. Assim, emoção pode ser entendida como a manifestação externa de algo que nos afetou internamente. "Contudo a maioria dos autores concorda em que as emoções são complexos estados de excitação de que participa o organismo todo.”’3 Cada estado emocional varia de cultura para cultura e suas manifestações

\footnotetext{
${ }^{1}$ CAPRA, Fritjof. O ponto de mutação, a ciência, a sociedade e a cultura emergente. Cultrix, São Paulo, 22 ed. 1999, p.55.

${ }^{2}$ DELGADO, Honorio. Curso de Psiquiatria - Psicopatologia - Psiquiatria Especial. Editorial Científico - Medica - 1978, Barcelo, Espanha, 6a ed. 1978, p. 76.

Nota: Una causa de alteración del estado de ánimo comparable com el normal efecto prolongado de lãs emociones violentas es lo que KURT SCHNEIDER llama reacción de fondo. Consiste en la repercusión de estados orgânicos (como um traumatismo cerebral o uma jaqueta) o psíquicos (p. e., un disgusto) sobre el curso ulterior de los sentimientos. Se trata del efecto causal, no de motivación, de tales estados. Lo anormal de esta repercusión comprende no solo la falta de riqueza y flexibilidade manifiesta em la vida afectiva, sino la intensidad y duración de la influencia del acontecimento sobre lãs vicisitudes de la dinâmica afectiva ulterior.

${ }^{3}$ BRAGHROLLI, E. Maria, BISI Guy et al. Psicologia Geral. 27 ed. Petrópolis-RJ, Vozes, 1995, p.108
} 
podem abarcar três indicadores que são os relatos verbais, a observação do comportamento e indicadores fisiológicos. ${ }^{4}$ Nos cultos e serviços religiosos, tanto a própria emoção como a sua manifestação tornaram-se parte do rito. O risco está presente quando certos estados emocionais são dinamizados de tal maneira que o participante perde a noção da realidade e não mais consegue raciocinar claramente sobre o que está acontecendo.

\subsection{Percepção distorcida}

O bem-estar emocional tornou-se um deus no nosso século, especialmente para as nações em franco desenvolvimento econômico. A prova incontestável disso pode ser observada nos mais variados livros de autoajuda, encontrados entre os títulos de editoras de cunho religioso ou não. Assim, crescem cada vez mais os modelos de pregação que ressaltam a fé dependente do sentir, como forma de aferição da presença de Deus na vida do crente. Porém, o mundo das sensações pode desenvolver uma percepção distorcida da realidade, criando assim um universo paralelo dissociado das questões da fé. E pior ainda, criando um deus particular, que deve se manter em estado de prontidão para atender a todas as demandas que causem desconforto emocional.

O cristianismo emocional tende a concentrar força nos momentos de prazer que a fé pode proporcionar, evitando as situações desconfortáveis às quais estamos todos propensos. Nesse tipo de viver cristão, o sofrimento é uma marca ou de falta de fé, ou de pecado oculto, em que o indivíduo está sempre em débito com o próprio bem-estar. Mascara-se assim a realidade da vida cristã apresentada nos evangelhos. Everton Bootz ${ }^{5}$ alerta-nos sobre as emoções ao escrever que "além dos pensamentos, as emoções também exercem um poder perturbador na vida das pessoas. Elas produzem uma distorção projetiva na interação entre o sujeito e a realidade". ${ }^{6}$

O sofrimento, a necessidade, as angústias, as privações são interpretados como nódoa da alma, e a subjetividade do sentir é que legitima a crença. Se

\footnotetext{
${ }^{4}$ Cf. op. cit.

${ }^{5}$ Everton Ricardo Bootz é pastor da Igreja Evangélica de Confissão Luterana no Brasil em Jaraguá - SC; doutor em Teologia pela EST - Escola Superior de Teologia - São Leopoldo/RS.

${ }^{6}$ LOTHAR, Carlos Hoch e THOMAS, (Org). Heimann. BOOTZ, Everton Ricardo. O efeito restaurador da espiritualidade e da mística cristã. In: Aconselhamento Pastoral e Espiritualidade. Anais do VI Simpósio de Aconselhamento e Psicologia Pastoral. São Leopoldo - EST - Sinodal, 2008 , p. 15.
} 
a minha sensação não é prazerosa então não é de Deus. Longe se encontra apropriar-se dos sentimentos de Cristo, que sofre, chora, se angustia, sangra e morre. Mais distante ainda encontra-se a esperança escatológica do corpo glorificado alcançado pela graça e salvação. A realidade não se mostra presente nesse caso. $\mathrm{O}$ que se observa claramente é que, em determinadas reuniões e cultos religiosos, quanto maior a ênfase numa parte da realidade, menos o indivíduo se perceberá como um ser holístico. Naquele momento cultual, o corpo serve apenas para extravasar o que, na linguagem psicanalítica, é chamado de catarse, eliminando as tensões e desconforto produzidos pelas vicissitudes da vida.

Quando a realidade escatológica está presente, a pregação se torna confiante e ousada, crendo que o caminho aberto por Cristo nos abre um meio de comunicação real com Deus. Se assim não acontece, o cristianismo emocional pode gerar uma vivência individual que desconsidera a essência da fé, não contribuindo para um testemunho público eficiente e integrado às mais diversas questões sociais. Esta ilusão inibe a liberdade cristã anunciada por Jesus, e dito por Thomas Merton como "uma liberdade que se entrega à ilusão torna-se responsável pela cegueira e escravidão que padece". ${ }^{7}$

Não se pode dizer algo sobre inculturação de emoções, mas não restam dúvidas de que em todas as culturas expressões emocionais são facilmente identificáveis. Choro, riso, tristeza e alegrias são universais e é bem verdade que seu significado varia de lugar para lugar, mas não se tornam incompreensíveis para os indivíduos de nenhuma comunidade. Conduzir o ser humano ao amadurecimento emocional pela revelação de Cristo é não permitir que a religião cristã seja reduzida a sentimentalismos subjetivos que em nada contribuem para a maturidade da fé.

\subsection{O que há de danoso num cristianismo puramente emocional?}

Um bom exemplo a ser percebido nos evangelhos é a reação de Judas frente ao desencanto de ver o líder maior entregue às forças romanas para $\mathrm{o}$ cumprimento da pena capital. A atitude do apóstolo pode ser tomada como analogia de uma fé emocional e de um cristianismo que, se não entendido, pode levar o incauto a cometer atos danosos, de impossível reparação. Segundo o relato de Mateus 27, Judas sofreu forte emoção, que culminou no suicídio. Sem muito esforço percebemos que a fé frágil, voltada a balizar a emoção, é

${ }^{7}$ MERTON, Thomas. O homem novo. Rio de janeiro, Agir, 1966, p. 141. 
ineficiente para impedir atitudes irreversíveis. Isso porque o homem tenta, por vezes, se colocar no lugar de Deus, fato amplamente perceptível na mesma modernidade que levou o homem a destituir Deus do centro do universo e se apresentar como suficientemente capaz de resolver seus problemas. Higuet assim define modernidade:

\begin{abstract}
Entende-se geralmente por modernidade um modo de civilização que se desenvolveu na Europa ocidental a partir do século XVI, com o Humanismo renascentista e a Reforma Protestante e que encontrou seus fundamentos filosóficos e políticos no século XVII e XVIII, com o pensamento empirista, racionalista e iluminista. ${ }^{8}$
\end{abstract}

Partindo desse pressuposto, o moderno é a evolução da mentalidade do homem como pensador da própria existência. Assim fazendo, ele derruba as certezas absolutas até então fossilizadas pelo período passado e especialmente defendidas pela igreja. Dessa forma o homem se centra em seu universo particular e sua autorrealização emocional está presente em todos os seguimentos por ele trilhados.

A religiosidade não está imune a essa nova forma de perceber o mundo. O cristianismo moderno também sofre com tal maneira de viver assumida pelo homem, que tenta transformá-lo em religião de sucesso material em que a felicidade deve ser alcançada a qualquer custo. Não são poucos os pregadores que dissimuladamente enraízam a "boa nova" na autorrealização pessoal, embasada em fortíssimas manifestações emocionais.

Nesse tipo de pregação não há espaço para a cruz nem para planos frustrados, mesmo por Deus, pois quem aponta a direção a seguir não é mais o Senhor, e sim quem, modernamente, pensa uma fé centrada na autorrealização, diferente do evangelho da graça; este por vezes nos adverte de que é perdendo que se ganha, é dando que se recebe.

O cristianismo de autorrealização emocional elege a prosperidade como deus, não atentando mais para os exemplos deixados pelos apóstolos do Senhor e negando a finalidade da criação, que é o encontro com Deus para o conhecimento de si mesmo, o que devolve ao homem a capacidade de perceber-se como humano, posto que ligado a Cristo. Por fim, qualquer autorrealização sem Cristo é apenas mais uma ilusão a que se apega o homem, que abandona o privilégio do amor de Deus expresso na pessoa de Jesus.

${ }^{8}$ HIGUET, Etienne A. (Org.) Teologia e modernidade. São Paulo, Fonte Editorial, 2005, p. 9 
Nosso objetivo nesta pesquisa não é aprofundar o que se pode perceber nas alterações emocionais causadas pela modernidade, mas apenas chamar a atenção para o que já existe de danoso na forma como tem sido pregado o evangelho por algumas instituições denominadas cristãs. Estas promovem verdadeiras sessões alienantes, sem preocupação com a consolidação da fé madura capaz de evitar desastres irreparáveis na vida do fiel. Banaliza-se a fé sincera, que mesmo em meio aos percalços diários, busca a vida.

\subsection{Judas e a emoção que se autoextermina}

No capítulo 27 do evangelho de Mateus ${ }^{9}$, lemos o relato do suicídio de Judas. Assim está escrito no verso 3: "Quando Judas, que o havia traído, viu que Jesus fora condenado, foi tomado de remorso e devolveu aos chefes dos sacerdotes e aos líderes religiosos as trinta moedas de prata". E ainda no verso 5: "Então Judas jogou o dinheiro dentro do templo e, saindo, foi e enforcou-se." (Grifo nosso). O que é o remorso? Entendido como emoção, como poderia ser percebido na prática? Sem aprofundar o significado do termo podemos dizer que:

“O remorso é também uma das manifestações típicas do sentimento de culpa. Ele não deve ser confundido com o arrependimento ou com o que a teologia chama de contrição. O remorso é uma conduta de autopunição que leva a reparar indefinidamente o passado vivido como uma condenação, uma acusação à pessoa. A expressão que aflora aos lábios de quem é por ele atingido assim se explica: 'A vida inteira hei de reprovar-me por causa disto'."10

No exemplo de Judas, observamos que se a fé se deixar levar pelas emoções, o final não será proveitoso. Com isso não atribuímos ao cristianismo o caráter de religião que vede a seus seguidores sentir ou expressar emoções. Pelo contrário, as expressões cristãs da fé estão repletas, em sua liturgia e forma de culto, de momentos verdadeiramente emocionantes, seja nas músicas e nos hinos de louvor, seja na pregação e na leitura do evangelho. Mas quando apenas a subjetividade emocional torna-se parâmetro para o amadurecimento da fé, o complemento que deveria acompanhar qualquer forma de expressão emocional fica gravemente comprometido. Apesar de ter

\footnotetext{
${ }^{9}$ Bíblia Sagrada - Nova Versão Internacional

10 “Culpa, Neurose e Pecado.” Iniciação à Teologia. v. 13, 2a Série. São Paulo, Paulinas, 1982, p. 31.
} 
caminhado com o Senhor e vivenciado momentos relevantes para o equilíbrio e a maturidade da fé, Judas não conseguiu manter a sobriedade necessária para superar o obstáculo por ele encontrado e mesmo criado, tornando-se réu, juiz e carrasco de si mesmo. O que nos parece é que, para Judas, o seu erro foi tão grande que nem todo o amor de Deus poderia perdoar. Quando não se consegue o controle emocional, encontrado ao longo das narrativas do evangelho e ensinado pelo Senhor em episódios diferentes, não há alternativa senão a forca.

\subsection{Pedro e o sentimento para a vida}

Os exemplos da vida de Pedro, o apóstolo, narrados nos evangelhos permitem-nos perceber que ele era o tipo de pessoa que facilmente deixava transparecer emoções e sentimentos. Embora não seja tarefa fácil distinguir emoção de sentimento, o hiato entre esses dois conceitos pode redundar em uma forma mais clara de autoconhecimento frente aos imprevistos que uma simples emoção é capaz de promover. Para o dr. Antônio Damásio, neurologista português, existe diferença entre emoção e sentimento. Em uma entrevista à revista Viver Mente \& Cérebro Scientific American, Ano XIII, No 143, de dezembro de 2004, ele assim define essa diferença:

$\mathrm{Na}$ linguagem corrente os dois termos são considerados sinônimos, o que mostra a estreita conexão que os une. Mas tentemos defini-los com precisão. Penso que uma emoção é um conjunto de reações corporais a certos estímulos. Quando temos medo, o ritmo cardíaco se acelera, a boca seca, a pele empalidece e os músculos se contraem - reações automáticas e inconscientes. Os sentimentos, por sua vez, surgem quando tomamos consciência destas "emoções" corporais, no momento em que estas são transferidas para certas zonas do cérebro onde são codificadas sob a forma de uma atividade neuronal. Para prosseguir com o exemplo, as modificações fisiológicas fazem com que experimentemos um sentimento de medo. ${ }^{11}$

\footnotetext{
${ }^{11}$ DAMÁSIO, Antonio. As bases biológicas das emoções. Revista: Viver Mente \& Cérebro Scientific American. XIII No143- Dezembro 2004. Disponível em <http://www.psiquiatriageral.com. br/cerebro/entrevista_antonio_damasio.htm >. Acesso em 21 de Agosto de 2011.

${ }^{\star}$ Nota: Sugiro a leitura da obra 1984, de George Orwell, para um melhor entendimento do que penso ser o controle mental do indivíduo e das massas.
} 
Percebemos então que os sentimentos têm o importante papel de trazer à memória algo que por algum motivo tenha fica esquecido no inconsciente. Poderiam então ser entendidos como instância psíquica que, partindo de um ponto específico no cérebro, levariam à percepção de certas emoções, sem que estas assumam o domínio de nossas ações ou reações. Mas o que isso tem a ver com o cristianismo e a fé? Entendemos que um cristianismo que tenha sua base instaurada apenas nas experiências emocionais não só deturpa a mensagem dos evangelhos, como impede que o crente se perceba como parte responsável das próprias ações. Não é segredo que algumas instituições, religiosas ou não, apelam para a exacerbação das emoções com vistas a manter o controle do indivíduo e da massa.* No caso do cristianismo, o risco está em que a alienação do indivíduo de sua realidade, juntamente com o envolvimento emocional temporário do número de participantes da celebração e do culto, poderá dinamizar processos prejudiciais à construção de uma fé equilibrada e madura.

Retornando ao exemplo de Pedro na narrativa apresentada nos evangelhos, quando o apóstolo nega conhecer Jesus, cai num estado emocional de autodecepção, mas podemos perceber, ao contrário do demonstrado pelo comportamento de Judas, a fé com sentimento emocionalmente equilibrado que, mesmo causando desconforto inicial, progride para o amadurecimento daquele que crê. Lemos no evangelho de Lucas 22.62: "Saindo dali, chorou amargamente". Percebemos então que apesar do extremo desconforto da experiência por que passava o apóstolo, o reconhecimento de sua falência não foi forte o suficiente para que seguisse o mesmo caminho de Judas, posto que aos olhos de Cristo ele, Pedro, entende o poder do amor, capaz de perdoar até o que se julga o maior dos traidores. Qual a diferença então? Exatamente a de que Pedro, mesmo inconscientemente, nutriu um sentimento pelo Senhor que foi além da simples emoção passageira ou de bem-estar. Ao sentir a dor de suas lágrimas, Pedro não se deixou dominar pela forte emoção que o sentimento fê-lo passar. Teve uma reação legitimamente humana. E o que é conhecer a Cristo senão perceber o que existe de humano em nós?

Um cristianismo desequilibrado impede que o crente entenda a oportunidade dada por Deus para novo começo, nova chance, vida nova. Cristianismo sólido, ao contrário, é fé que liberta para viver e não para morrer, pois a vida é expressão do cuidado de Deus pela criatura. 


\section{Conclusão}

A insuficiência do cristianismo emocional tem se apresentado, nos tempos denominados modernos, como fuga da realidade e mais uma forma dissimulada de dominação do homem. Bem diferente do cristianismo apresentado por Jesus aos que com ele caminharam e entenderam a mensagem do Reino de Deus. Não se tem conhecimento de que o homem já tenha descoberto a vacina que o imunize das questões controversas da alma. O que sabemos pela história do cristianismo é que homens e mulheres que vivenciaram a fé madura conseguiram suportar as mais terríveis e desgastantes emoções sem que estas assumissem o controle da situação.

Nossa esperança é que os teólogos, pelo estudo e ensino sério das escrituras, bem como as instituições cristãs comprometidas com a expansão do Reino de Deus, não permitam que a fé em Deus mediada por Jesus seja banalizada por emoções que se compram nas escuras esquinas daqueles que fazem da fé banca de negócios. Que tal oposição impeça o triunfo dos predadores de seres humanamente indefesos que anseiam descobrir que pela fé em Cristo Jesus, a esperança ainda pode tornar-se realidade. Para vida e não para a morte.

\section{Referências Bibliográficas}

Bíblia Sagrada - Nova Versão Internacional

BRAGHROLlI, E. Maria, BISI Guy et al. Psicologia Geral. 27 ed. Petrópolis-RJ, Vozes, 1995, p. 108.

CAPRA, Fritjof. O ponto de mutação, a ciência, a sociedade e a cultura emergente. Cultrix, São Paulo, 22 ed. 1999, p. 55.

“Culpa, Neurose e Pecado.” Iniciação à teologia. V. 13, 2ª Série. São Paulo, Paulinas, 1982, p. 31.

DAMÁSIO, Antonio. As bases biológicas das emoções. Revista: Viver Mente \& Cérebro Scientific American. XIII Nº143 - Dezembro 2004. Disponível em <http://www.psiquiatriageral.com.br/cerebro/entrevista_antonio damasio.htm>. Acesso em 21 de Agosto de 2011.

DELGADO, Honorio. Curso de Psiquiatria - Psicopatologia - Psiquiatria Especial. Editorial Científico - Medica - 1978, Barcelo, Espanha, $6^{a}$ ed. 1978, p. 76.

HIGUET, Etienne A. (Org.) Teologia e modernidade. São Paulo, Fonte Editorial, 2005, p.9 
LOTHAR, Carlos Hoch e THOMAS, (Org). Heimann.BOOTZ, Everton Ricardo. $O$ efeito restaurador da espiritualidade e da mística cristã. In: Aconselhamento Pastoral e Espiritualidade. Anais do VI Simpósio de Aconselhamento e Psicologia Pastoral. São Leopoldo - EST Sinodal, 2008, p.15

MERTON, Thomas. O homem novo. Rio de janeiro, Agir, 1966, p.141

\section{Francisco de Assis Souza dos Santos}

Doutorando em Teologia pela PUC-Rio

Professor na Faculdade Unida de Vitória - ES.

Desenvolve pesquisa na área de Aconselhamento Pastoral e Psicanálise.

Artigo Recebido em 23/09/2011

Artigo Aprovado em 28/11/2011 